\title{
Pathfinder probes the weather on Mars
}

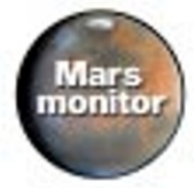

[LONDON] After spending more than a month exploring the surface of Mars, the lander Pathfinder is being allowed by the US National Aeronautics and Space Administration to rest at night, in order to cut down on the charging and discharging that depletes its batteries.

The hope is that the lander can keep working for several more months, using solar power. Sojourner is still taking chemical measurements of rocks and soil patches. But over the past couple of weeks, more attention has been focused on the lander's measurements of martian weather. Weather conditions have been found to be steady, with large regular daily swings in pressure and temperature.

But two meteorological oddities have been observed. One is rapid fluctuations in both temperature and pressure. Ground temperatures can change by $20^{\circ} \mathrm{C}$ within a few minutes, and pressures can also alter over the same timescale. These fluctuations are probably very local, and may be caused by 'dust devils'.

The second oddity is a striking temperature drop within a few feet of the surface. Unlike the Viking landers, Pathfinder can measure temperature and wind speed as a function of height, using thermocouples and wind socks at different heights on its mast. It has found that the temperature drop from ground level to five feet above the surface can be more than $40^{\circ} \mathrm{C}$.

Such information is vital in characterizing the 'boundary-layer' interactions between the martian atmosphere and surface, including factors such as turbulence and rate of heat flow from the surface. Little information has previously been available about such issues, and the findings have significant implications for understanding the behaviour of the atmosphere as a whole, as well as for the way in which wind is involved in erosion and deposition of material on the surface.

Understanding how the winds change, and how they are affected by local terrain and by tides, could be of more than just academic interest. "These local winds will be important if we ever go ballooning on Mars in order to cover substantial distances," says Brian Toon of the University of Colorado.

The dust carried by the winds into the atmosphere also plays an important part in controlling the weather by absorbing heat from the Sun. Two weeks ago, the flight team released pictures of sunrises and sunsets, showing the atmospheric dust.

Some of these pictures also show clouds of water vapour in the early morning - confirmation of the idea that pre-dawn condensa-

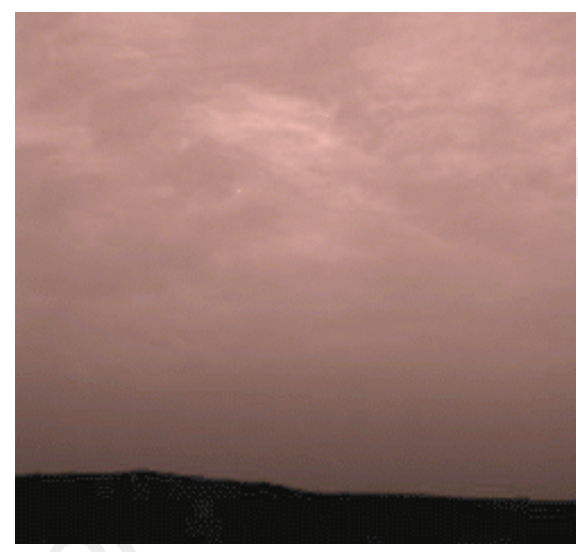

Pink planet: the martian sky is coloured pink by ice particles formed on dust in early morning.

tion into clouds helps to move water around the planet. In photographs taken in the early morning, the sky is coloured pink by ice that has condensed on dust particles some $16 \mathrm{~km}$ above the surface (see above).

The main reason for the stability in the weather conditions experienced by Pathfinder so far is that it has landed during a season of low pressure, when there is minimal atmospheric activity. But the martian autumn will bring dust storms, promising to make the weather more interesting to observers on Earth. Stephen Battersby

\section{'Neutral' mechanism sought to fund environmental research}

[WASHINGTON] US lawmakers have been left groping for ways to fund scientific research that will not be seen in environmental controversies as either biased or flawed, following the recent bitter debate in Congress about new air pollution standards (see Nature 388, 5; 1997).

A committee of the House of Representatives has even dusted off a longstanding proposal to create a National Institute for the Environment (NIE), which could conduct environmental research free of the regulatory agenda that many critics say taints the scientific activities of the Environmental Protection Agency (EPA).

Although the Washington-based Committee for the NIE has long been lobbying for such an institute, the idea has in the past received little political attention. But members of the House appropriations subcommittees that oversee the budgets of the EPA and the National Science Foundation have told the foundation to produce a report by next April on how it might set up and finance such an institute.

Two senior members of the Senate, the Democrat leader, Thomas Daschle of South Dakota, and Chuck Robb (Democrat, Virginia), have gone further, trying - unsuccessfully - to persuade their colleagues on the appropriations committee to add between $\$ 20$ million and $\$ 50$ million to the science foundation's budget next year, to enable it to start setting up the NIE.

But, despite this apparent revival in political interest, the concept still has relatively few supporters in Washington, and is unlikely to survive. The White House opposes it, and even many environmental groups are lukewarm. One member of a green lobbying organization calls the NIE "a solution in search of a problem".

Critics of the proposal point out that several federal agencies already conduct peerreviewed environmental research, and say that creating a new one would waste research dollars on extra administrative overheads. Some question whether it is always desirable to separate scientists from regulators.

They point to the lack of coordination between the Occupational and Health Safety Administration, which drafts regulations to protect workers, and the National Institute for Occupational Safety and Health, which conducts research on job-related hazards. Often, say critics, the two agencies work on unrelated problems, so that the relevant scientific data are not always available when they are needed for drafting legislation.

But, even if the NIE is shelved, Congress appears anxious to turn to bodies other than the EPA for environmental research. The House appropriations committee, for example, gave a $\$ 35$ million increase to the EPA for research on air pollutants, but wants the money transferred to the National Institute of Environmental Health Sciences in North Carolina, part of the National Institutes of Health.

Senate appropriators added less money (\$8 million) for air pollution research, but also specified that it should not go to the EPA. The funds would be used to set up five competitively selected, university-based research centres, which would investigate the health effects of ozone and airborne particulate matter.

Whatever Congress decides, EPA scientists may already be experiencing the political fallout from the defiant stand taken earlier this year by Carol Browner, the administrator of the agency, in favour of tighter air pollution regulations. They can only hope that the controversy will not set back the significant progress made by the agency recently in improving its reputation for high-quality research. 